\title{
A formação de leitores assumida como proposta pedagógica: das contradições às congruências
}

The development of readers as a pedagogical proposal: from contradictions to congruencies

https://doi.org/10.34112/2317-0972a2017V35n69p115-130

Gomercindo GHIGGI

Priscila Monteiro Chaves ${ }^{2}$

Rogéria Novo da Silva ${ }^{3}$

RESUMO: O presente artigo busca, a partir de uma investigação com um grupo de professores de uma escola pública de rede municipal, através de entrevistas semiestruturadas, pensar os entraves da atuação de professores na formação de leitores, considerando o vasto discurso utilizado pelos docentes com o advento do letramento. $\mathrm{O}$ referencial teórico adotado concentra-se mormente nos preceitos teóricos de Paulo Freire (e seus comentadores), bem como de autores outros que se destinam a pesquisar a leitura. Como conclusão, propõe-se que as práticas sociais cotidianas adentrem os programas escolares em projetos assumidos pelos professores, enquanto movimento realizado na própria instituição, problematizando o que se entende como tarefa da escola para a formação de leitores e buscando indicativos que enfrentem os limites concretos que o processo de escolarização vem imprimindo ao conhecimento cultural e cientificamente organizado.

PALAVRAS-CHAVE: Formação de leitores; formação permanente; proposta pedagógica.

ABSTRACT: Based on a research with a group of teachers from a public municipal school, through semi-structured interviews, the present article seeks to explore the barriers of the performance of teachers, taking into consideration the vast empty discourse adopted by

1. Universidade Federal de Pelotas, Pelotas, RS, Brasil.

2. Universidade Federal de Pelotas, Pelotas, RS, Brasil.

3. Rede Municipal de Ensino de Pelotas, Pelotas, RS, Brasil. 
teachers with the advent of literacy. The theoretical framework chosen focuses mainly on the theoretical principles of Paulo Freire (and his followers), as well as other authors who research reading. In conclusion, it is proposed that daily social practices step into school programs as projects undertaken by the teachers, as a movement carried out in the institution itself, questioning what they understand as a responsibility of the school regarding the development of readers and searching for indicators that deal with the concrete limits that the educational process has been impressing on the cultural and scientifically structured knowledge.

KEYWORDS: Development of readers; lifelong education; pedagogical proposal.

\section{INTRODUÇãO}

Este texto se propõe a discutir os entraves na formação do leitor, colaborando com a indicação de quefazeres ${ }^{4}$ à formação dos professores a partir de contribuições da Linguística, da Filosofia, da Sociologia da Educação e da Pedagogia. Tem como objeto de análise respostas de professoras de uma escola pública da rede municipal de ensino de uma cidade do interior gaúcho, que assumem como prioridade a formação de leitores, percebendo as aproximações e os distanciamentos que se vislumbram em relação ao discurso assumido e aos processos teórico-metodológicos inerentes a esses processos.

As professoras que participaram deste trabalho, respondendo a três questões-chave, são da mesma escola e se reúnem semanalmente ${ }^{6}$ para discutir sobre demandas próprias das suas turmas. A discussão envolve quatro quefazeres (FREIRE, 2005) norteadores: 1) o conhecimento da realidade concreta dos alunos; 2) o

4. Quefazer, conforme Paulo Freire (2005), se coloca como oposição ao puro fazer, pelo reconhecimento que o docente é um ser de práxis, ou seja, porque a ação está imbricada por uma teoria, respondendo a um ímpeto que não dicotomiza a busca da direção e do conteúdo da ação da própria ação, não aceitando, em se tratando de uma prática radicalmente progressista, que se considere uns como sujeitos do pensar e outros sujeitos do fazer (em outras palavras, a já conhecida distinção entre homo sapiens e homo faber), impondo como caminho ético e político do quefazer.

5. 1) Qual o papel da escola em relação à formação de leitores?; 2) Que conhecimentos/habilidades são condizentes com o comportamento de um leitor?; 3) Que ações a escola pode/deve ter para formar leitores?

6. A escola das referidas professoras organiza-se de forma que o corpo docente, uma vez por semana, se reúna com a coordenadora pedagógica, individualmente, a fim de discutir sobre as situações concretas da turma pautadas pelos 4 indicativos apontados. Quinzenalmente, o grupo se reúne e discute temas centrais que vão surgindo como necessários ao longo dos encontros semanais individuais. Estas são as principais características que fizeram com que os pesquisadores elegessem a referida instituição dentre outras nove escolas de ensino fundamental na zona norte e leste da cidade. 
conhecimento dos processos de constituição de saberes em todas as áreas; 3) o conhecimento dos objetos de conhecimento; e 4) o conhecimento próprio do fazer docente, que se constrói na relação direta entre os três primeiros a partir de um processo de reflexão constante.

Os referenciados diálogos registrados a partir de uma entrevista semiestrutura$\mathrm{da}^{7}$ não são exaustivamente expostos, uma vez que o objetivo central não é relatar e sim sobre eles refletir, mas pensados à luz das teorias de Emília Ferreiro e de Delia Lerner (no que compete às questões da área da leitura); e de Paulo Freire e alguns de seus comentadores (concernentes às questões sociofilosóficas). As respostas fornecidas devem ser entendidas também como motivadoras das inquietações aqui apresentadas, permeando a construção deste texto que possui caráter mais ensaístico. Por isso, faz-se ao leitor o alerta para o cuidado com algumas generalizações, pois o ponto de partida para as reflexões aqui apresentadas é um olhar crítico-reflexivo a partir dessa inserção na escola pública. Assim, não há a intenção de proporcionar o conhecimento preciso de um conjunto de características de uma determinada população, mas de problematizar algumas questões, a partir de uma visão global da formação de leitores, identificando possíveis aspectos que influenciam ou podem ser influenciados nesse processo.

\section{O CONTEXTO DA DISCUSSÃO}

A organização escolar, no momento atual, (sobre)vive aos impactos que a Escola Nova the impôs, ao disseminar a "ideia de fundamentar o ato pedagógico na ação, na atividade da criança”" (GADOTTI, 2001, p. 142). Na esteira dessa máxima, "este vigoroso movimento de renovação da educação depois da criação da escola pública burguesa" (GADOTTI, 2001, p. 142) pôs a Pedagogia a dialogar de forma mais próxima com a sociologia educacional e com a psicologia do desenvolvimento, o que, de certa forma, o distanciou do seu próprio objeto - o pedagógico -; e se encaminhou para uma cisão com a filosofia, uma vez que se centrou nos processos de aquisição

7. Em conformidade com Sampieri (SAMPIERI; COLLADO; LUCIO, 2006, p. 381), "as entrevistas semiestruturadas $[. .$.$] se baseiam em um guia de assuntos ou questões e o pesquisador tem a liberdade de$ introduzir mais questões para a precisão de conceitos ou obter maior informação sobre os temas desejados”. A opção pela entrevista semiestruturada se justifica pela sua flexibilidade, que favorece o diálogo e a expressão mais autêntica por parte do entrevistado. $O$ intento foi não permitir a saída muito brusca da temática nem perder a possibilidade de aprofundar algumas das respostas. 
dos objetos de conhecimento e nas formas com que o currículo poderia se rearticular em torno desse novo diálogo. Em síntese, distanciou-se dos fins do fazer pedagógico, centrou-se no puro fazer e divorciou-se da busca pela direção e pelo conteúdo do seu quefazer. A questão central é entender que consequências esses encontros e desencontros produzem para a formação de leitores, considerando a quase inexistência de ganhos e os consideráveis prejuízos, para assim rearticular os movimentos que os professores realizam em torno dos objetos próprios do seu fazer.

Nos processos de escolarização, de forma mais explícita, registrou-se a influência das contribuições do psicólogo suíço Jean Piaget, que, nas últimas décadas do século $\mathrm{XX}$, adentraram os cursos de formação de professores, provocando uma reorganização do conhecimento em relação à aprendizagem, pela transferência, para o aluno, da centralidade até então dada ao professor, ou seja, passou-se a atentar, na Pedagogia, para os processos de aprendizagem, relegando a segundo plano os processos de ensino, como se não houvesse uma relação estreita entre este e aquela. Assim, a pergunta que por ora a Pedagogia buscou responder deixou de ser como se ensina, sendo substituída por como se aprende. No entanto, essa polarização em torno da Pedagogia e da Psicologia deixa escapar outras duas tão importantes e definidoras quanto essas, são elas, para que se ensina e o que se ensina.

É na resposta integradora dessas perguntas - como se aprende? Para quê? O quê? Como se ensina? - que os processos de escolarização poderão responder de forma mais satisfatória às necessidades dos sujeitos, no sentido de melhor se relacionar com as condições de existência de cada um deles. Refletindo sobre a ação docente, é na busca por respostas a essas quatro perguntas que se torna possível redefinirmos as práticas pedagógicas para além de modismos ou de alterações das dinâmicas efetivadas em sala de aula, mas no sentido de reformular as diretrizes desse fazer, dimensionando o caráter ético e político da docência. Oliveira-Formosinho (2008, p. 28), pela perspectiva freiriana, perfaz essa denúncia apontando que há não apenas uma distância entre as propostas consecutivas e a realidade concreta, mas também uma tendência à manipulação nominalista, levando "a uma vivência meramente retórica da inovação em que uma nova roupagem, por vezes apenas uma nova cosmética, envolve a mesma realidade". Percebe-se ainda que, em outras tantas vezes, há a apropriação de algumas proposições como prescrições, tendo em vista sua aplicabilidade mais direta, mesmo que elas não possuam a intenção em sua origem.

Dessa maneira reducionista, a influência da teoria piagetiana na educação, sobretudo nos anos iniciais, ocorre em razão do reconhecimento de que as crianças 
precisam desenvolver seu raciocínio lógico pela manipulação do concreto, deslocando-se posteriormente para relações abstratas. Na prática, é possível evidenciar a busca por um conjunto de procedimentos metodológicos específicos das pesquisas feitas pelo suíço, como se elas respondessem pedagogicamente sobre o ato de ensinar. Como uma das consequências, há um conjunto de indicadores avaliativos de desempenho e de prontidão para aprender, que não superam as formas até então adotadas pela maioria dos professores nos processos de ensino, pois desconsideram a dimensão investigativa desse processo. Nesse mesmo sentido, não se tem evidenciado a consciência docente de que o saber escolar se distingue do saber tal como ele se constitui e circula através das relações sociais, desconsiderando a necessidade de reflexão sobre a transposição didática (LERNER, 2002) inerente ao processo de escolarização. Desse modo, tem-se uma redução da teoria epistemológica para a averiguação das condições para a aprendizagem, sem que se redimensionem as questões relacionadas ao ensino. $\mathrm{O}$ que faz com que em diversos momentos o docente se sirva dos dados advindos das referenciadas avaliações para justificar a aprendizagem ou não dos alunos.

Da mesma forma se têm percebido as interpelações realizadas pelos professores a partir das leituras movidas pelas pesquisas de Emília Ferreiro, que no Brasil começou a influenciar as discussões, sobretudo no meio acadêmico, a partir da década de 8o, com a publicação do livro Psicogênese da Língua Escrita, traduzido para o português em 1985. Tanto Piaget quanto Ferreiro, de forma representativa, impulsionaram um movimento de redefinição de práticas pedagógicas que, salvo equívocos, demonstram positivamente uma preocupação por parte dos professores com uma aprendizagem realmente realizável sob o ponto de vista do aluno enquanto sujeito cognoscente. A partir disso, percebe-se uma proliferação de slogans - frases e expressões - partidários desses novos conhecimentos que, julga-se, já não podem ser omitidos: considerar o erro do aluno; respeitar o ritmo de cada aluno; desenvolver o raciocínio lógico-matemático, entre tantos outros slogans que, quanto mais são ditos, mais causam a impressão de que menos são compreendidos.

No mesmo sentido com que a Psicologia adentrou os processos de escolarização, a Sociologia da Educação foi requerendo uma nova postura dos professores diante do fazer pedagógico. Esses passaram a refutar ações e decisões marcadamente denunciadas pelas mencionadas teorias, mas investiram em tantas outras do mesmo cunho, sem perceber o fato, e não redefiniram as matrizes de seu pensamento, 
o que compromete proclames políticos e ideológicos e tantas outras decisões que precisam ser tomadas cotidianamente.

De certa forma, a contradição pode ser notada no momento em que os professores se esquivam do envolvimento com uma atitude filosófica que os remeteria, necessariamente, a pensar no projeto de educação que possuem; e, nesse sentido, buscariam não só por elementos para o puro fazer, mas se inclinariam ao quefazer, e as mudanças não ocorreriam a partir de meras prescrições, mas das denúncias que as teorias fazem (FREIRE, 1978).

A legitimação da Pedagogia como área do conhecimento possibilitou-lhe uma abrangência maior e, assim, maior possibilidade de contar com conceitos híbridos, em diálogo com outras áreas. As reflexões sobre a teoria da aprendizagem enfocadas pela Psicologia, assim como as teorias desenvolvidas pela Sociologia da Educação, possibilitam dar uma dimensão muito mais complexa às demandas dos processos de escolarização. Se se ganha em amplitude, incorre-se na armadilha dos reducionismos, das fragilidades, dos modernismos e da manipulação nominalista.

Da mesma forma que é possível identificar uma distância entre os discursos proferidos na escola e as ações dos professores em relação aos processos de aquisição da leitura e da escrita, pode-se perceber esse distanciamento em relação ao conceito de letramento ${ }^{8}$. Na maioria das vezes, conforme estudo de Ribeiro e Batista (2009), utilizam-no como método de ensino ou acredita-se na existência de um método de alfabetização correlato, desconsiderando sua relação com a participação em práticas sociais de leitura.

No campo filosófico essa questão ganha expressividade, atrelada ao equívoco no entendimento sobre o que significa o respeito à realidade dos sujeitos (FREIRE, 2005), que adentrou o ideário pedagógico, sem que se considerasse a radicalidade

8. Não se entrará aqui em discussões analíticas a respeito do referido conceito; toma-se este como "estado ou condição de quem não apenas sabe ler e escrever, mas cultiva e exerce as práticas sociais que usam a escrita" (SOARES, 2009, p. 47). Mas, ao mesmo tempo, entende-se que este (re)emerge da insatisfação do conceito alfabetização e que, em virtude disso, ainda se configura como um termo um tanto quanto caro aos linguistas, visto que o processo não inicia após a aprendizagem do código escrito. Em entrevista concedida a Pelegrini, Ferreiro (2003, p. 28) advoga que letramento "passou a ser o estar em contato com distintos tipos de texto, o compreender o que se lê. Isso é um retrocesso. Eu me nego a aceitar um período de decodificação prévio àquele em que se passa a perceber a função social do texto. Acreditar nisso é dar razão à velha consciência fonológica”. Reforça ainda esta assertiva sua defesa de alfabetização como um contínuo de desafios cada vez maiores enfrentados pelo aluno mediante cada tipo de texto sem experiência prévia, independente de sua idade e nível escolar, "yo enseño en el nivel de maestría y doctorado, pero sigo alfabetizando a mis alumnos, porque es la primera vez que, como lectores, se enfrentan a investigaciones publicadas en revistas especializadas y, como escritores, deben producir por primera vez un tipo peculiar de texto académico que se llama 'una tesis'” (FERREIRO, 2008, p. 20). 
que essa formulação possui. Se for levado em consideração que a formação de leitores perpassa a proposição das formas próprias, como as práticas de leitura se processam na sociedade pela escola, não é possível desconsiderar a realidade dos sujeitos. Sobre esta questão, a contribuição de Paulo Freire é inegável, não exatamente porque formulou um método, no sentido restrito de utilização do campo pedagógico, mas porque seu método, muito mais do que analítico-sintético, como ele mesmo o classifica em Educação como prática da liberdade, é uma reformulação dos meios e dos fins da alfabetização. Como bem advoga Soares, em síntese, Freire apresenta: "[...] uma concepção de alfabetização que transforma o material e o objetivo com que se alfabetiza, as relações sociais em que se alfabetiza, é uma concepção que põe o método a serviço de uma certa política e filosofia da educação" (2008, p. 119).

É justamente esse movimento teórico proposto por Freire que se sente deficitário na escola. Os professores, instigados por essas teorias, buscam, de um lado, propostas com uma apresentação diferente das tradicionais, rechaçadas por diversas teorias, mas, ao colocarem em prática atividades sem a devida reflexão política e filosófica, contribuem para um esvaziamento dessas mesmas teorias. Por outro lado, o fato de o discurso estar disseminado torna mais exaustivo propor uma reflexão sobre os limites das práticas que se efetivam, uma vez que os professores dizem já a terem feito. E se faz necessário, portanto, adentrar no campo da reflexão da prática pedagógica, enfrentar os limites éticos, políticos, epistemológicos e ideológicos que são impostos e rever a concepção de formação continuada que sobressai nos discursos. ${ }^{9}$

\section{OS LIMITES DE UMA MUDANÇA SUBSTANCIAL}

É notório que a escola precisa lidar com a incoerência entre os projetos propostos e as ações efetivadas, bem como entre os objetivos propostos pelos parâmetros e a prática pedagógica da escola pública. A formação do leitor tem sido uma das principais preocupações do contexto escolar, pois percebe-se a busca incessante por métodos cada vez mais promissores, atualizados, divertidos e agradáveis, do ponto de vista

9. De forma geral, os processos de formação continuada ocorrem sob a marca da "anunciação" e da "oferta”, ou seja, se apresentam como "pacotes” de conteúdos inéditos e omissos nas práticas docentes, mas dificilmente respondem às questões enfrentadas pelos professores na cotidianidade do fazer docente, na medida em que retiram dos próprios professores a possibilidade de tematizar seus limites e definir estratégias de pesquisa para a busca de novos encaminhamentos necessários. 
estético ou cosmético. Entretanto, conforme Oliveira-Formosinho (2008), em sua matriz teórica se perpetuam formas de compreender a aprendizagem pela mecanização e pela memorização. Muda-se o ensino, mas pouco se altera a aprendizagem!

Através do discurso que circunda a escola ${ }^{10}$, quando esse se torna meramente uma retórica, é possível perceber que não se questiona a atribuição dada a ela de formar leitores, mesmo que essa tarefa seja partilhada com a sociedade. $O$ que nos remete à percepção de que não há uma acomodada ideia de aproximação entre conceitos fundamentais sobre os processos necessários para esse fim. Por vezes, os professores carecem de reflexão sobre a justificativa para buscar essa formação, bem como carecem de noções sobre os processos intrínsecos para tal, que se traduziriam em maiores condições de optar por oferecer algumas atividades ou não. Essa carência pode ser percebida a partir da seguinte afirmação de uma das professoras que participaram desta pesquisa, em relação ao seu trabalho, no que tange à formação de leitores no processo de alfabetização:

É bem difícil, pois os alunos não têm o hábito de ler em casa e nem os familiares cultivam este hábito. Isso faz com que os alunos não despertem para o gosto da leitura e isso influencia até mesmo na alfabetização, demorando mais que outros alunos para aprender a escrever e a ler. A escola precisa incentivar e mostrar o prazer da leitura. (Professora 3)

Nessa fala, a professora aponta para uma questão a ser pensada pela perspectiva que vimos adotando: o equívoco de considerar formar leitores como sinônimo de gostar de ler. Essa não distinção pode inicialmente ser refletida amparada pelo lançamento de um dos imperativos midiáticos mais divulgados nos últimos tempos a respeito dessa carência: "Vamosfazer do Brasil um país de leitores". Por um longo período esse constituía o tema da campanha de incentivo à leitura do Ministério da Educação Tempo de Leitura, tendo como objetivo um maior estímulo a essa atividade dentro e

10. Entre os professores que atuam nas escolas, não há um entendimento generalizado sobre o tema da formação de leitores. Entretanto, ainda que a amostra da pesquisa seja relativamente restrita (três professoras), percebe-se que elas conhecem, com propriedade, as características do corpo docente e discente, bem como da instituição. Isso nos permite conjeturar que o conjunto de suas respostas possibilita compreender as características do tipo do trabalho que vem sendo desenvolvido na escola, de modo que as respostas fornecidas por elas representam "expressão do indivíduo que fala e também daqueles que o fazem falar como fala, bem como de qualquer tensão ou contradição que os possa inter-relacionar. [...] Elas não apenas expressam a si mesmas, os seus próprios conhecimentos, sentimentos e aspirações, mas também algo diferente delas mesmas [...] e isso se funde com o que elas realmente pensam, vêem e sentem" (MARCUSE, 1973, p. 183). 
fora da sala de aula ${ }^{11}$. Porém, a pergunta negligenciada era: que espécie de incentivo é dado, a fim de que os estudantes e a comunidade em geral se tornem leitores?

Segundo dados da campanha, às crianças era permitido que levassem para casa os livros da escola para que os lessem juntamente com suas famílias e tomassem o gosto pela leitura. Conforme categoricamente enfoca Daniel Pennac, em seu livro lançado na França em 1992, Comme un Roman, é possível considerar essas intenções como bons começos, desde que entendidos como tal, como algo que demande uma continuidade, com o objetivo de humanização/emancipação do sujeito, e não apenas $o$ gosto pelo gosto. Carência semelhante à que se entende no discurso na professora recém-citada.

Entende-se que essa não distinção também aponta o reducionismo da compreensão sobre o que seria formar leitores, uma vez que muito pouco ou quase nada se tem definido sobre essa tarefa e sobre os encaminhamentos políticos, estéticos, filosóficos e teórico-metodológicos necessários para esse fim.

Ainda na resposta da Professora 3, pode-se perceber a consideração de que a participação em práticas cotidianas de leitura e escrita dá às crianças elementos importantes para sua alfabetização, mas não é possível supor que, assim considerando, passe a rever suas práticas pedagógicas com vistas a oferecer tais processos. Esse reconhecimento serve apenas para justificar a aprendizagem ou não aprendizagem dos alunos, retirando do professor a responsabilidade que possui nesse processo.

Nota-se ainda que, em virtude da grande gama de informações pontuais advindas de jornais, revistas sobre educação, programas de televisão, ou até mesmo na interação com outros professores, em eventos da área, há um conjunto de ações metodológicas que devem ser refutadas pelos professores. $\mathrm{O}$ discurso da escola do século XXI já mostra que o docente sabe que não deve elaborar suas aulas a partir de atividades meramente mecânicas, mas precisa lidar com a disseminação e a velocidade que as informações alcançam e com a transformação do privado em público através das redes sociais. Porém, os professores parecem não saber o porquê de não o fazer ou, pior, parecem desconhecer não apenas o porquê de trabalhar conforme sugerem as metodologias e os métodos substitutivos, mas também as prováveis consequências para as formas de organização sociocultural da sociedade.

A prática educativa parece ter naturalizado suas ações, o que faz com que a relação entre ação escolar e propósitos educativos fundamentais se perca, e os professores ajam apenas como executores e/ou apenas proclamem discursos tidos

11. Informações disponíveis em: <http://agenciabrasil.ebc.com.br/node/628879>. Acesso em: 20 out. 2015. 
como inovadores ou imperativos à pratica docente. Percebe-se a necessidade de retomar o sentido da tarefa docente (FREIRE, 1998) e de desenvolver uma atitude filosófica que os leve a refletir sobre os fundamentos das mudanças instituídas, o que demanda disciplina intelectual.

Retoma-se então a reflexão sobre letramento e as formas pelas quais vem sendo incorporado pela escola. O Ministério da Educação, através de seus documentos e diretrizes curriculares, aponta para uma prática que se sustenta nos fundamentos propostos pelo letramento, sobretudo em relação aos três primeiros anos iniciais ${ }^{12}$. No entanto, as iniciativas de discutir a respeito de como implementar práticas condizentes com tais diretrizes e resoluções são ainda restritivas e segmentadas. Embora a proposta do Pró-Letramento - Mobilização pela Qualidade da Educação ${ }^{13}$ - se proponha a atender a todos os professores em exercício nas séries iniciais do ensino fundamental das escolas públicas, na prática, no município onde esta pesquisa foi realizada, cada escola pode inscrever um número determinado de professores, desde que não corresponda a sua totalidade. Como consequência, há um descompasso entre fins e meios, fazendo com que a escola se aproprie de mudanças mais institucionais, sem a devida discussão de seus fundamentos e a necessária revisão dos preceitos teórico-metodológicos.

O Conselho Nacional de Educação, fixando as Diretrizes Curriculares Nacionais para o Ensino Fundamental de nove anos, propõe a continuidade da aprendizagem nos três primeiros anos do ensino fundamental. Essa definição precisa ser vista a partir da própria aprendizagem e não do ponto de vista apenas da promoção automática, mas, tendencialmente, os professores vislumbram apenas o fato de não haver mais repetência nos três primeiros anos. Nem mesmo discutem a serviço de que essas reformulações são feitas do ponto de vista econômico e de financiamento internacional. $\mathrm{E} o$ aspecto ainda mais preocupante é o fato de sequer refletirem sobre questões de cunho mais pedagógico, como o acompanhamento da aprendizagem, as formas de divulgar os dados obtidos por esse acompanhamento, que, em síntese, sustenta uma reorganização da prática educativa e, por isso, do sistema escolar.

12. Conforme Resolução CNE/CEB no 7, de 14 de dezembro de 2010, que Fixa Diretrizes Curriculares Nacionais para o Ensino Fundamental de nove anos, em seu artigo 30, parágrafo primeiro, que explicita como devendo ser assegurado nos três primeiros anos de escolarização "a alfabetização e o letramento" (BRASIL, 2010, p. 8).

13. Programa de formação continuada de professores para a melhoria da qualidade de aprendizagem da leitura/ escrita e matemática nos anos/séries iniciais do ensino fundamental, realizado pelo MEC, em parceria com universidades que integram a Rede Nacional de Formação Continuada e com adesão dos estados e municípios. 
Pode-se perceber um conjunto de indicações que vão sendo incorporadas ao discurso dos professores no que se refere às ações necessárias para formar leitores, desvelando a superficialidade com que esses elementos são analisados. A fala de uma das professoras aponta esse reducionismo, quando responde que é preciso "proporcionar situações reais de uso da leitura e da escrita" e complementa, afirmando as formas pelas quais se pode concretizar o referido objetivo: "fazer uso de cartazes para informar e buscar informações, procurar notícias e informações em jornais e revistas, se utilizar de cartas e bilhetes para comunicar algo" (Professora 1).

É notório que ações que fazem parte do discurso corrente a respeito das práticas de letramento já são conhecidas. Os professores entendem e são perfeitamente capazes de listar do que uma criança necessita, em termos de materiais de apoio, para iniciar seu processo de formação como leitor. $\mathrm{O}$ que se torna de suma importância ser aqui percebido é o fato de que a reflexão a respeito da estrutura da língua não é concebida em nenhum momento nesse diálogo. Nossa afirmação é legitimada quando, em outra pergunta semelhante àquela recém-exposta, a respeito do posicionamento do contexto escolar para com os professores dos anos iniciais, a mesma professora diz que

[...] a escola, é uma das instituições que deve disponibilizar o maior número possível de "objetos" de leitura e proporcionar práticas de leitura onde esses "objetos" possam ser explorados. Tipo: disponibilizar livros, revistas, coleções, enciclopédias, dicionários, jornais, gibis, folhetos informativos, panfletos, cartas, bilhetes, recados... e proporcionar situações onde todos esses objetos de leitura possam ser explorados (Professora 1).

Qual é a função do professor, no contato dos alunos com esses "livros, revistas, coleções, enciclopédias, dicionários, jornais, gibis, folhetos informativos, panfletos, cartas, bilhetes, recados"? A responsabilidade da escola precisa transcender a oferta dos portadores de textos, uma vez que não existe pó mágico que os conduza à leitura e à escrita. Dessa forma, percebe-se que há a apropriação de um discurso em evidência e que a aproximação com diferentes portadores textuais é exigência de uma prática escolar que pretende formar leitores. No entanto, por si só, não garante a almejada formação. Como já dito, os professores, em sua maioria, redefinem alguns aspectos de sua prática, sobretudo os mais práticos, que não necessariamente refletem uma reformulação de concepção epistemológica (FREIRE, 1998). 
O grande avanço a ser aqui reconhecido é a utilização de portadores reais de textos, bem como a ideia de que a diferenciação e a boa adaptação de gênero já fazem também parte do processo de leitura. Porém não é possível perceber sua relação com as práticas sociais de leitura, o letramento e a reflexão acerca da língua.

Como consequência, há o reconhecimento - revelado por testes - de que as crianças escolarizadas não aceitam a contação de histórias em uma bula de remédio, bem como não aceitam prescrições médicas em uma carta. A inquietação que paira é a de que a sistematização da estrutura da língua não está sendo fator de tão grande preocupação quanto a utilização e o contato com os materiais. As coerentes estratégias metacognitivas que a criança utiliza ainda estão sendo consideradas como "erros", e em suas dificuldades ortográficas não são feitas distinções entre regularidades e irregularidades da língua, o que é extremamente perigoso, pois nega ao leitor o domínio da metalinguagem e também, consequentemente, sua autonomia como falante/escrevente de sua língua.

Nesse ponto é que reside, principalmente, a relevância de uma formação permanente, como será apontado na próxima seção, tendo em vista a possibilidade de desvelamento das concepções verdadeiras que os professores possuem em relação aos temas da aprendizagem e do ensino, levando em consideração o caráter inconcluso dos cursos de graduação.

\section{Caminhos possíveis: Algumas hipóteses}

Embora tenham sido esboçados até aqui alguns limites - vislumbrados a partir de entrevistas -, seja em relação às ciências, seja em relação à coerência entre o discurso e o entendimento que os professores possuem, quer-se terminar o artigo apresentando as fissuras que se identificam, a partir do diálogo com as professoras, como possibilidade de avanço, no sentido de formar leitores dentro do ambiente escolar.

Lerner (2002) indica três pontos que não podem ser omitidos quando se elaboram propostas pedagógicas para a formação de leitores. Em primeiro lugar: considerar que essa tarefa é específica da pedagogia, sendo sua função interagir com os conhecimentos de outras áreas (como, por exemplo, a linguística), a fim de propor estratégias de ações condizentes com os objetivos e as finalidades relativas a uma dada concepção; segundo: ter em conta a natureza da instituição escolar, colocada no contexto social desde a modernidade, que lida com práticas excludentes, de 
hierarquização, organizando-se numa lógica temporal que desconsidera o sujeito aprendente; terceiro: ponderar que as práticas sociais, ao serem ensinadas, perdem por isso alguns de seus traços próprios. A partir da consciência desses desafios é que se torna possível controlá-los.

Há, no conjunto de diálogos realizados até aqui, a evidência da necessidade de que a formação dos professores seja repensada a partir dos limites que se apresentam. Para tanto, é preciso que se realize uma revisão do que se tem proposto como formação continuada, com intenção de "mirar desde adentro los acontecimientos que se suceden cuando la formación es concebida como un proceso continuo y asumida como un trabajo cooperativo" ${ }^{14}$ (LERNER, 2009, p. 13).

Ancorando-se nessa ideia de renovação da aprendizagem, a formação continuada é pensada no momento em que se reconhece que os sujeitos estão em constante processo de aprendizagem e se constata a velocidade com que os conhecimentos se tornam obsoletos. Como estratégia inicial, organizam-se cursos "compensatórios" de temas que se avaliam como frágeis em relação ao entendimento dos professores. Assim, as ideias de Ferreiro, por exemplo, adentraram a escola. Em um segundo momento, correspondendo às críticas dos próprios docentes, que denunciaram a incompatibilidade da apresentada teoria com as possibilidades práticas da docência, ou seja, apontaram a dificuldade de reorganizar suas práticas pedagógicas a partir do novo referencial, houve uma redefinição desses cursos para a forma de oficinas. Isso acarretou a oferta de um conjunto de atividades, tidas por essa teoria como plausíveis e condizentes com a construção do conhecimento. Os professores, por vezes, "aplicando" essas atividades sem a devida compreensão de sua finalidade, tampouco reconsiderando sua concepção sobre a construção do conhecimento, continuaram com uma postura de condução apoiada na memorização, transformando as atividades em meras "novas roupagens". Agiam, nesse sentido, em prol do puro fazer.

Compreende-se então a reflexão comunitária/coletiva como uma necessidade de um terceiro movimento: o da formação permanente. Nesse, o grande diferencial não está no conhecimento que se "oferta", mas na origem dele (FREIRE, 1978), bem como em sua forma. Acontecendo dentro da escola e a partir das situações-limite ${ }^{15}$

14. Tradução nossa: "olhar por dentro os acontecimentos que se sucedem quando a formação é concebida como um processo contínuo e assumida como um trabalho cooperativo”.

15. As situações-limite devem ser compreendidas como possuidoras de uma possibilidade e não como limitadoras, como obstáculos intransponíveis (FREIRE, 2005). Dialogam com a denúncia das condições 
enfrentadas pelos professores, essa formação considera todos os professores pesquisadores e se inclina para a necessidade da coletividade e da relação direta com a realidade dos sujeitos, sejam os alunos, sejam os próprios professores.

Freire pontua sobre esse processo de formação, afirmando que a rigorosidade possibilita caminhar em direção à superação das contingências concretas que são impostas. Tanto Freire quanto Lerner apontam a necessidade de lançar mão de um estudo rigoroso, em busca das formas próprias com que a Pedagogia constrói seus caminhos, sem que, para isso, se aproprie erroneamente das formulações de outras áreas, nem tampouco as desconsidere.

É aqui intuída a possibilidade de formar leitores na instituição escolar no momento em que forem assumidos os riscos e os desafios de ampliar o que a escola vem oferecendo, em termos de leitura, ao fazer com que as práticas sociais cotidianas adentrem os programas escolares e as salas de aula. Esse movimento precisa ser feito na própria instituição, por seus professores, porém é necessário que se reflita coletivamente sobre as questões apresentadas ao longo deste texto.

É preciso problematizar o que os professores entendem como tarefa da escola em relação à formação de leitores, para buscar indicativos que apontem para o enfrentamento dos limites concretos (FREIRE, 2000) que o processo de escolarização vem imprimindo ao conhecimento cultural (FREIRE, 1978) e cientificamente organizado. É nos movimentos de reflexão e de investigação-ação que professores podem tornar-se autônomos em relação a sua formação como formador de leitor, possibilitando um constante processo de revisitar a prática e a sua teoria, direcionando o fazer a um inacabado momento de rever-se.

\section{CONSIDERAÇões Finais}

Como tarefa da escola e da formação de alfabetizadores se inscreve a necessidade de avançar nas discussões a respeito das práticas sociais de leitura, denunciando a descaracterização que a leitura toma na escola e que contribui para a formação de leitores escolares, e não de leitores críticos. Mas, para além disso, se reivindica um processo de formação permanente dos professores, para que compreendam tanto as concepções de educação que ancoram os diferentes modismos quanto a necessidade de reflexão a respeito da língua desde o início da formação de leitores.

sócio-históricas a caminho do anúncio do que é possível, ou seja, o inédito viável (FREIRE, 200o). 
Avançar nessas discussões significa refletir sobre que leitor se almeja, que situações/ações envolvem o ser leitor, que instrumentos são necessários para que se possa ser realmente um leitor. Aqui é o princípio, denunciando a necessidade de uma nova reflexão, visto que, no conjunto de denúncias e anúncios feitos pelo texto que aqui se apresenta, pode-se apontar que a possibilidade de a escola formar leitores passa pela formação dos professores. E essa não pode ser fragmentada, tampouco imposta, mas deve considerar as dimensões linguísticas, pedagógicas, didáticas, epistemológicas, filosóficas, sociológicas, psicológicas, éticas, políticas e estéticas e ser assumida pelos professores como investigadores da própria prática.

\section{REFERÊNCIAS}

ADORNO, T.W. Teoria da semicultura. Trad. Newton Ramos de Oliveira. Educação e Sociedade, Campinas, ano XVII, n. 56, p. 388-411, dez. 1996.

BRASIL. Conselho Nacional deEducação. Resolução CNE/CEB n. ${ }^{\circ}$, de 14 de dezembro de 2010, que fixa Diretrizes Curriculares Nacionais para o Ensino Fundamental de 9 (nove) anos. Disponível em: $<\mathrm{http}$ :// portal.mec.gov.br/index.php?option=com_content\&view=article\&id=12748\&Itemid=866>.

Acesso em: 10 out. 2015.

GADOTTI, M. História das ideias pedagógicas. 8. ed. São Paulo: Ática, 2001.

FERREIRO, E. Reflexões sobre alfabetização. São Paulo: Cortez, 2000. . Alfabetização e cultura escrita. Entrevista concedida a Denise Pellegrini. Nova Escola - A revista do Professor. São Paulo, p. 27-30, maio 2003.

. Leer y escribir en un mundo cambiante. In: FERREIRO, E. Pasado y presente de los verbos leer y escribir. Buenos Aires: Fondo de Cultura Económica, 2008. p. 11-39.

FERREIRO, E.; TEBEROSKY, A. A psicogênese da língua escrita. Porto Alegre: Artmed, 1999.

FREIRE, P. Cartas a Guiné-Bissau: registros de uma experiência em processo. Rio de Janeiro: Paz e Terra, 1978. . Professora sim, Tia não: cartas a quem ousa ensinar. São Paulo: Olho d' água, 1998. . Pedagogia da indignação: cartas pedagógicas e outros escritos. São Paulo: Unesp, 2000. . Pedagogia do oprimido. 5o. ed. rev. e atual. Rio de Janeiro: Paz e Terra, 2005.

LERNER, D. Ler e escrever na escola: o real, o possível e o necessário. Tradução de Ernani Rosa. Porto Alegre: Artmed, 2002.

LERNER, D.; STELLA, P.; TORRES, M. Formación docente en lectura y escritura: recorridos didacticos. Buenos Aires: Paidós, 2009.

MARCUSE, H. A ideologia da sociedade industrial. Rio de Janeiro: Zahar, 1973.

OLIVEIRA-FORMOSINHO, J. A investigação-ação e a construção de conhecimento profissional relevante. In: PIMENTA, Selma Garrido; FRANCO, Maria Amélia S. Pesquisa em Educação possibilidades investigativas da pesquisa-ação. São Paulo: Loyola, 2008. v. 2. p. 27-39. 
RIBEIRO, A. E. A.; BATISTA, A. R. O letramento e suas formas de apropriação: análise das narrativas de professores. In: CONGRESSO DE LEITURA DO BRASIL, 17., 2009, Campinas. Anais do $17^{\circ}$ COLE, Campinas, SP: ALB, 2009. Disponível em: <http://www.alb.com.br/portal. html>. Acesso em: 15 ago. 2011. ISSN: 2175-0939.

SAMPIERI, R. H.; COLLADO, C. H.; LUCIO, P. B. Metodologia de pesquisa. 3. ed. São Paulo: McGraw-Hill, 2006.

SOARES, M. Alfabetização e letramento. 5. ed. São Paulo: Contexto, 2008. . Letramento: um tema em três gêneros. 3. ed. Belo Horizonte: Autêntica, 2009.

\section{SOBRE OS AUTORES}

Gomercindo Ghiggi é graduado em Filosofia (Universidade Católica de Pelotas), tem Mestrado em Filosofia (Pontifícia Universidade Católica do Rio Grande do Sul) e Doutorado em Educação (Universidade Federal do Rio Grande do Sul). É professor da Universidade Federal de Pelotas. Tem experiência na área de Filosofia da Educação, com pesquisa nos seguintes temas: Paulo Freire, educação popular, formação de professores, autoridade, liberdade e educação.

E-mail: gghiggi@terra.com.br

Priscila Monteiro Chaves é graduada em Licenciatura em Letras PortuguêsFrancês e respectivas literaturas (Universidade Federal de Pelotas), tem Mestrado e Doutorado em Educação (Universidade Federal de Pelotas). É professora temporária da Universidade Federal do Rio Grande do Sul. Tem experiência na área de Filosofia da Educação, com pesquisa nos seguintes temas: ensino de literatura, formação humana, teoria crítica da sociedade, alfabetização e letramento.

E-mail: pripeice@gmail.com

Rogéria Novo da Silva é graduada em Pedagogia (Universidade Federal de Pelotas) e tem Mestrado em Educação (Universidade Federal de Pelotas). É professora da Rede Municipal de Ensino de Pelotas. Tem experiência na área de Filosofia da Educação, com pesquisa nos seguintes temas: formação de professores, formação permanente e teoria freiriana.

E-mail:rogerians@gmail.com

Recebido em o5 de maio de 2016 e aprovado em 04 de janeiro de 2017. 